\title{
Association between childhood fractures and poverty: population based study
}

\author{
Andrew D Stark, George C Bennet, David H Stone, Parveen Chishti
}

Childhood mortality from injuries is known to be higher in children from deprived backgrounds, ${ }^{1}$ but the picture for non-fatal injuries is less clear. Fractures provide a measure of injury rates that is independent of distance from accident and emergency departments. ${ }^{2}$ Lyons et al found no difference in fracture rates in children from deprived and affluent areas. ${ }^{2}$ This, however, contradicts our anecdotal impression from accident and emergency and fracture clinics. We therefore conducted a retrospective population based study to assess the association between deprivation and childhood fracture rates in our area.

\section{Participants, methods, and results}

Greater Glasgow Health Board area has a definable population served by six acute hospitals. We identified new fractures in children aged 0-14 years in 1997 from accident and emergency logbooks and clinic attendances at each hospital. Twenty two of the 4512 case notes were untraceable. We retrieved and reviewed all traceable records.

We assessed deprivation levels within postcode sectors using neighbourhood-type analysis. This has been used extensively since 1985 by the health board to compare health in areas of differing social deprivation. $^{3}$ Cluster analysis using 29 demographic variables identified from census data identified eight groups of postcode sectors broadly similar in social and environmental factors. We subdivided these into three groups. - Affluent (groups 1 and 2): mostly owner-occupied housing with professional or skilled workforce

- Middle (groups 3-6): wide range of mixed tenure housing with mixture of skilled and unskilled workforce

- Deprived (groups 7 and 8): local authority housing in inner city and peripheral housing estates; high unemployment.

We obtained population statistics from the 1991 census. We compared fracture rates for deprived versus affluent, middle versus affluent, and deprived versus middle groups using the test for two proportions. A Bonferroni adjustment was carried out. The spread of age was similar in all groups. Sex bias was excluded by assessing boys and girls separately.

A total of 2712 fractures were sustained in 2662 children in 1997, from a child population of 167972. Children living in deprived areas had a significantly higher fracture rate than those in affluent areas (table). Despite a consistent trend, the differences between middle and affluent groups and between deprived and middle income groups were smaller and not consistently significant.

\section{Comment}

We found that children living in deprived areas have higher fracture rates than those from affluent areas. This finding is in keeping with previous reports of higher

\begin{tabular}{|c|c|c|c|c|c|c|}
\hline & \multicolumn{3}{|c|}{ Fracture rate/10 000 children } & \multicolumn{3}{|c|}{$P$ value for comparison } \\
\hline & Deprived & Middle & Affluent & $\begin{array}{c}\text { Deprived } v \\
\text { affluent }\end{array}$ & $\begin{array}{c}\text { Middle } v \\
\text { affluent }\end{array}$ & $\begin{array}{c}\text { Deprived } v \\
\text { middle }\end{array}$ \\
\hline Boys & 214.1 & 197.0 & 184.0 & 0.021 & 0.243 & 0.150 \\
\hline Girls & 134.1 & 132.4 & 93.8 & $<0.001$ & $<0.001$ & 0.864 \\
\hline Total & 175.3 & 166.0 & 140.1 & $<0.001$ & $<0.001$ & 0.231 \\
\hline
\end{tabular}

mortality from injury. ${ }^{1}$ A similar study in south Wales, however, found no correlation between childhood fracture rates and deprivation. ${ }^{2}$ This may be because of differences in the levels of deprivation in the populations of Glasgow and south Wales. In addition, we used different methods to assess levels of poverty. Townsend scores, which were used by Lyons et al, are difficult to apply in Scotland because population statistics are based on postcode sectors. The neighbourhood analysis is a similar tool, which includes the four variables used in the Townsend score and a further 25 demographic factors. Basic methodological differences seem unlikely to account for such a big difference in results.

Lyons reported an overall fracture incidence of $361 / 10000$ compared with $161 / 10000$ in our study. The incidence in Glasgow closely matches previously published childhood fracture rates. ${ }^{45}$ It would be useful to monitor the effects of programmes targeting deprivation and more general projects of urban regeneration and health promotion on fracture rates.

Department of
Orthopaedic
Surgery, Royal
Hospital for Sick
Children, Glasgow
G3 8SJ
Andrew D Stark
specialist registrar
George C Bennet
consultant surgeon
PEACH Unit,
University of
Glasgow, Royal
Hospital for Sick
Children
David H Stone
director
Parveen Chishti
statistician
Correspondence to:
A Stark
andrew.stark1@
ntlworld.com

BMJ 2002;324:457

Contributors: GCB and DHS had the original idea for this study, initiated its design, and advised on writing the paper and its revision. ADS carried out all patient identification, data collection, and data analysis and wrote the paper and its revision. PC did the statistical analysis and advised on writing the paper. GCB is the guarantor.

Funding: None.

Competing interests: None declared.

1 Morrison A, Stone DH, Redpath A, Campbell H, Norrie J. Trend analysis of socioeconomic differentials in deaths from injury in childhood in Scotland 1981-95. BMJ 1999;318:567-8.

2 Lyons RA, Delahunty AM, Heaven M, McCabe M, Allen H, Nash P. Incidence of childhood fractures in affluent and deprived areas: population dence of childhood fractures in
based study. BMJ 2000;320:149.

3 Greater Glasgow Health Board Health Information Unit. Indicators of deprivation. Glasgow: Greater Glasgow Health Board, 1995.

4 Landin LA. Epidemiology of children's fractures. J Paediatr Orthopaedics Part B 1997;6:79-83.

5 Lyons RA, Sellstrom E, Delahunty AM, Loeb M, Varilo S. Incidence and cause of fractures in European districts. Arch Dis Child 2000;82:452-5. (Accepted 23 October 2001)

\section{Endpiece}

The world's trouble

The trouble with the world is that the stupid are cocksure and the intelligent full of doubt.

Bertrand Russell (1872-1970)

Submitted by Himanshu Sharma, senior house officer, Southampton 